\title{
Current Evidence on Vitamin C, D, and Zinc Supplementation for COVID-19 Prevention and/or Treatment
}

\author{
Andrea Giacalone ${ }^{1^{\star}}$, Luca Marin ${ }^{2}$, Massimiliano Febbi ${ }^{2}$, Marcos Roberto Tovani-Palone ${ }^{3^{\star \star}}$
}

\author{
${ }^{1}$ University of Rome Tor Vergata, Department of Industrial Engineering, Rome, ITALY \\ ${ }^{2}$ Asomi College of Sciences, Department of Research, Marsa, MALTA \\ ${ }^{3}$ Ribeirão Preto Medical School, University of São Paulo, Ribeirão Preto, BRAZIL \\ *Corresponding Author: giacalonericci@yahoo.it \\ ${ }^{\star \star}$ Corresponding Author: marcos_palone@hotmail.com
}

Citation: Giacalone A, Marin L, Febbi M, Tovani-Palone MR. Current Evidence on Vitamin C, D, and Zinc Supplementation for COVID-19 Prevention and/or Treatment. Electron J Gen Med. 2021;18(5):em311. https://doi.org/10.29333/ejgm/11099

\begin{tabular}{lll}
\hline ARTICLE INFO & $\begin{array}{l}\text { ABSTRACT } \\
\text { Received: } 5 \text { Jun. 2021 }\end{array} \quad \begin{array}{l}\text { In this article, we discuss current evidence on some of the dietary supplements that have been most commonly } \\
\text { used for coronavirus disease 2019 (COVID-19) prevention and/or treatment, including vitamin C, vitamin D, and } \\
\text { Accepted: 11 Jul. 2021 }\end{array}$
\end{tabular}

Keywords: COVID-19, pandemics, ascorbic acid, vitamin D, zinc

Dear Editor,

The role of food sources immune-boosting nutrients has been much discussed during the coronavirus disease 2019 (COVID-19) pandemic. Moreover, a nutritional deficiency could be a predisposing factor to development and progression of a viral infection [1]. However, there is still no global consensus regarding the use of dietary supplements and/or medicines in the recommendations for COVID-19 management [2,3]. Knowledge of the benefits and risks associated with the use of dietary supplements is of considerable importance, especially if they are used in order to prevent and/or treat severe acute respiratory syndrome coronavirus 2 (SARS-CoV-2) infection cases. In this context, pharmacists should ensure that patients are informed of the current lack of evidence to demonstrate the effectiveness of dietary supplements for that purpose [4]. Here, we discuss some of the dietary supplements that have been most commonly used for COVID-19 prevention and/or treatment, including vitamin C, vitamin D, and zinc.

\section{VITAMIN C}

Vitamin $C$ has a number of physiological properties and its intravenous use is believed to be effective in inhibiting cytokines production in acute respiratory distress syndrome cases [5]. Vitamin C properties include its acting as an enzymatic cofactor and antioxidant factor, roles in proteoglycan deglycanation, in the free radicals scavenger process, histone dealkylation, and homeostasis of subcellular compartments [6]. Some clinical trials have looked at the use of vitamin $C$ as part of a respiratory diseases management plan [7]. Recently, a team of Chinese doctors stated that they have effectively treated over 50 patients affected by mild to acute COVID-19 with large intravenous (IV) vitamin C doses $(10,000$ -
$20,000 \mathrm{mg} / \mathrm{d}$ ) for a period of 8-10 hours [8]. In fact, vitamin C has modes of action that could be relevant to acute respiratory infections management, such as antioxidant, antiinflammatory, antithrombotic, and immunomodulatory functions [9]. However, it should be borne in mind that high doses of vitamin C can promote the development of kidney stones, especially in people with high oxalate levels [4].

In addition, surprisingly, in an open randomized clinical trial conducted in Pakistan, the use of standard therapy in combination with IV vitamin C resulted in early regression of COVID-19 symptoms and reduced length of hospital stay [10]. In contrast, other studies performed in the USA show that vitamin $C$ treatment caused no change in COVID-19 patients $[11,12]$. It should be noted that the results of many ongoing randomized clinical trials are still pending and currently available studies do not provide scientifically strong evidence for the use of vitamin C as a treatment for COVID-19.

\section{VITAMIN D}

Vitamin D obtained by sun exposure, food, and supplements must undergo two hydroxylation reactions to be converted into calcitriol (the biologically active form of vitamin D) [13]. Maintaining sufficient vitamin D levels through adopting a healthy diet, consuming vitamin supplements, and sun exposure is essential for good health. Patients should carefully follow the guiding principles for daily vitamin D intake based on: maximum intake levels to optimize general health and a need for intake due to vitamin deficiency. It is recommended to follow medical advice and avoid doses higher than the upper limit (4000IU/day; $100 \mu \mathrm{g} /$ day) in the hope of treating or preventing COVID-19 [14]. Prolonged intake of more 
than 4000 IU of vitamin D is considered to be potentially dangerous and may cause hypercalcemia [4].

On the other hand, given the possible association between hypovitaminosis D and COVID-19, vitamin D supplementation has been indicated as a useful treatment due to its antiinflammatory and antithrombotic properties [15]. Vitamin D deficiency appears to be associated with more severe clinical stages of COVID-19, so its assessment may be a useful analysis for possible therapeutic interventions [16]. However, the use of high doses of vitamin $D$ does not significantly reduce the mortality rate or length of stay [17].

\section{ZINC}

Administration of zinc lozenges has been associated with a reduction in the duration and severity of cold symptoms. In this case, zinc should be administered within 24 hours of symptoms development, at doses around $80 \mathrm{mg} / \mathrm{day}$ and for less than two weeks [18-20]. Zinc supplementation increases mucociliary clearance, anti-oxidative effects, and epithelial integrity. Furthermore, it decreases viral replication and the likelihood of hyperinflammation, as well as maintains antiviral immunity, reducing lung damage and the risk of secondary infections [21]. In this regard, zinc combined with medicines could eventually be effective in COVID-19 patients only if administered prior to the onset of the cytokine storm [22].

\section{FINAL CONSIDERATION}

Current COVID-19 treatment recommendations make no mention of dietary supplements and do not include the use of drugs not tested in clinical trials $[23,24]$. Although the use of dietary supplements has created high expectations in the population, there is no robust evidence in the literature supporting the effectiveness of their use for COVID-19 prevention and/or treatment.

Author contributions: All authors have sufficiently contributed to the study, and agreed with the results and conclusions.

Funding: No funding source is reported for this study.

Declaration of interest: No conflict of interest is declared by authors.

\section{REFERENCES}

1. Name JJ, Souza ACR, Vasconcelos AR, Prado PS, Pereira CPM. Zinc, vitamin D and vitamin C: perspectives for COVID19 with a focus on physical tissue barrier integrity. Front Nutr. 2020;7:606398. https://doi.org/10.3389/fnut.2020. 606398 PMID:33365326 PMCID:PMC7750357

2. Centers for Disease Control and Prevention (CDC). Healthcare workers: information on COVID-19. Atlanta: CDC, 2021. Available at: https://www.cdc.gov/coronavirus/ 2019-ncov/hcp/index.html (Accessed: 5 June 2021).

3. Mado H, Reichman-Warmusz E, Dudek D, Warmusz O. Is vitamin $D$ supplementation protective against coronavirus disease 2019 (COVID-19)?. Electron J Gen Med. 2021;18(2):em283. https://doi.org/10.29333/ejgm/9762

4. Adams KK, Baker WL, Sobieraj DM. Myth busters: dietary supplements and COVID-19. Ann Pharmacother. 2020;54(8):820-6. https://doi.org/10.1177/10600280209280 52 PMID:32396382
5. Boretti A, Banik BK. Intravenous vitamin C for reduction of cytokines storm in acute respiratory distress syndrome. PharmaNutrition. 2020;12:100190. https://doi.org/10.1016/ j.phanu.2020.100190 PMID:32322486 PMCID:PMC7172861

6. Mandl J, Szarka A, Bánhegyi G. Vitamin C: update on physiology and pharmacology. $\mathrm{Br} \mathrm{J}$ Pharmacol. 2009;157(7):1097-110. https://doi.org/10.1111/j.14765381.2009.00282.x PMID:19508394 PMCID:PMC2743829

7. Hoang BX, Shaw G, Fang W, Han B. Possible application of high-dose vitamin $C$ in the prevention and therapy of coronavirus infection. J Glob Antimicrob Resist. 2020;23:256-62. https://doi.org/10.1016/j.jgar.2020.09.025 PMID:33065330 PMCID:PMC7553131

8. Cheng RZ. Can early and high intravenous dose of vitamin C prevent and treat coronavirus disease 2019 (COVID-19)? Med Drug Discov. 2020;5:100028. https://doi.org/10.1016/ j.medidd.2020.100028 PMID:32328576 PMCID:PMC7167497

9. Carr AC, Rowe S. The emerging role of vitamin $C$ in the prevention and treatment of COVID-19. Nutrients. 2020;12(11):3286. https://doi.org/10.3390/nu12113286 PMID:33121019 PMCID:PMC7693980

10. Kumari P, Dembra S, Dembra P, Bhawna F, Gul A, Ali B, et al. The role of vitamin $C$ as adjuvant therapy in COVID-19. Cureus. 2020;12(11):e11779. https://doi.org/10.7759/ cureus.11779 PMID:33409026 PMCID:PMC7779177

11. Capone S, Abramyan S, Ross B, Rosenberg J, Zeibeq J, Vasudevan V, et al. Characterization of critically ill COVID19 patients at a Brooklyn safety-net hospital. Cureus. 2020;12(8):e9809. https://doi.org/10.7759/cureus.9809 PMID:32850261 PMCID:PMC7444967

12. Thomas S, Patel D, Bittel B, Wolski K, Wang Q, Kumar A, et al. Effect of high-dose zinc and ascorbic acid supplementation vs usual care on symptom length and reduction among ambulatory patients with SARS-CoV-2 infection: the COVID A to $Z$ randomized clinical trial. JAMA Netw Open. 2021;4(2):e210369. https://doi.org/10.1001/ jamanetworkopen.2021.0369 PMID:33576820 PMCID: PMC7881357

13. Institute of Medicine (US) Committee to review dietary reference intakes for vitamin $D$ and calcium. Dietary reference intakes for calcium and vitamin D. Ross $A C$, Taylor CL, Yaktine AL, Del Valle HB, editors. Washington (DC): National Academies Press (US); 2011. PMID:21796828

14. Lanham-New SA, Webb AR, Cashman KD, Buttriss JL, Fallowfield JL, Masud T, et al. Vitamin D and SARS-CoV-2 virus/COVID-19 disease. BMJ Nutr Prev Health. 2020;3(1):106-10. https://doi.org/10.1136/bmjnph-2020000089 PMID:33230499 PMCID:PMC7246103

15. Verdoia M, De Luca G. Potential role of hypovitaminosis D and vitamin $D$ supplementation during COVID-19 pandemic. QJM. 2021;114(1):3-10. https://doi.org/10.1093/ qjmed/hcaa234 PMID:32735326 PMCID:PMC7454841

16. Ricci A, Pagliuca A, D’Ascanio M, Innammorato M, De Vitis C, Mancini R, et al. Circulating vitamin D levels status and clinical prognostic indices in COVID-19 patients. Respir Res. 2021;22(1):76. https://doi.org/10.1186/s12931-021-01666-3 PMID:33658032 PMCID:PMC7928197

17. Murai IH, Fernandes AL, Sales LP, Pinto AJ, Goessler KF, Duran CSC, et al. Effect of a single high dose of vitamin D3 on hospital length of stay in patients with moderate to severe COVID-19: a randomized clinical trial. JAMA. 2021;325(11):1053-60. https://doi.org/10.1001/jama.2020. 26848 PMID:33595634 PMCID:PMC7890452 
18. Hemilä H, Chalker E. The effectiveness of high dose zinc acetate lozenges on various common cold symptoms: a meta-analysis. BMC Fam Pract. 2015;16:24. https://doi.org/ 10.1186/s12875-015-0237-6 PMID:25888289 PMCID: PMC4359576

19. Hemilä H, Petrus EJ, Fitzgerald JT, Prasad A. Zinc acetate lozenges for treating the common cold: an individual patient data meta-analysis. $\mathrm{Br} \mathrm{J}$ Clin Pharmacol. 2016;82(5):1393-8. https://doi.org/10.1111/bcp.13057 PMID:27378206 PMCID:PMC5061795

20. Prasad AS, Fitzgerald JT, Bao B, Beck FW, Chandrasekar PH. Duration of symptoms and plasma cytokine levels in patients with the common cold treated with zinc acetate. A randomized, double-blind, placebo-controlled trial. Ann Intern Med. 2000;133(4):245-52. https://doi.org/10.7326/ 0003-4819-133-4-200008150-00006 PMID:10929163

21. Wessels I, Rolles B, Rink L. The potential impact of zinc supplementation on COVID-19 pathogenesis. Front Immunol. 2020;11:1712. https://doi.org/10.3389/fimmu. 2020.01712 PMID:32754164 PMCID:PMC7365891
22. Carlucci PM, Ahuja T, Petrilli CM, Rajagopalan H, Jones S, Rahimian J. Hydroxychloroquine and azithromycin plus zinc vs hydroxychloroquine and azithromycin alone: outcomes in hospitalized COVID-19 patients. medRxiv. 2020. https://doi.org/10.1101/2020.05.02.20080036. 05.02. 20080036

23. Bhimraj A, Morgan RL, Shumaker AH, Lavergne V, Baden L, Cheng VC, et al. Infectious Diseases Society of America Guidelines on the treatment and management of patients with COVID-19. Clin Infect Dis. 2020:ciaa478. https://doi.org/10.1093/cid/ciaa478 PMID:32338708 PMCID:PMC7197612

24. de Faria Coelho-Ravagnani C, Corgosinho FC, Sanches FFZ, Prado CMM, Laviano A, Mota JF. Dietary recommendations during the COVID-19 pandemic. Nutr Rev. 2021;79(4):38293. https://doi.org/10.1093/nutrit/nuaa067 PMID:32653930 PMCID:PMC7454801 